\title{
REVIEW
}

\section{Effects of lifestyle factors on fertility: practical recommendations for modification}

\author{
Mathias Abiodun Emokpae and Somieye Imaobong Brown \\ Department of Medical Laboratory Science, School of Basic Medical Sciences, University of Benin, Benin City, Nigeria \\ Correspondence should be addressed to M A Emokpae: mathias.emokpae@uniben.edu
}

\begin{abstract}
The role that lifestyle factors play in fertility issues has generated some amount of interest and questions among stakeholders. This review aims to highlight the impact of lifestyle behaviors on the fertility potential of an individual and what can be done to prevent or improve reproductive outcomes. Relevant published articles on the effect of lifestyle behaviors were obtained from Medline, Pubmed and Google scholar search engines for the study. The review of the literature indicates a negative impact of modifiable lifestyle factors such as fat-rich diets, delayed childbearing/age of starting family, smoking, alcohol misuse, sexual behavior, anxiety/depression and perception/beliefs were associated with fertility. The ensuing stress precipitates social behaviors such as excessive alcohol and caffeine consumption, tobacco smoking, misuse of recreational drugs/medications, which increases the risk of sexually transmitted diseases and infection leading to infertility. Practical recommendations to modify lifestyle behaviors and the impact of misconception of Assisted Reproductive Technology in the treatment of infertility are discussed. The need to make appropriate behavioral changes to stem the tide of infertility in Nigeria is imperative. More reproductive health education is needed to create the necessary awareness of the etiologies of infertility and the importance of in vitro fertilization treatment as a means of conceiving 'natural' babies is suggested.
\end{abstract}

\section{Lay summary}

Scientific evidence has suggested that modifiable lifestyle factors (consumption fat-rich diets, delayed childbearing/age of starting family, smoking, alcohol misuse, sexual behavior, anxiety/depression and perception/beliefs) play important roles in the general health and wellbeing of individuals including fertility. Evidence exists of an association between lifestyle behaviors and infertility in both men and women. Understanding the various processes through which modifiable lifestyle behaviors impair fertility will help to assist in the management of affected individuals. We conducted a comprehensive review of published studies to assess how lifestyle factors inhibit fertility and practical ways to ameliorate them. This review also deals with the misconception of Assisted Reproductive Technology in the treatment of infertility. The need to make appropriate behavioral changes to stem the tide of infertility in Nigeria is imperative. More reproductive health education is needed to create the necessary awareness of the causes of infertility and the importance of in vitro fertilization in the treatment of infertility.

Key Words: - lifestyle behaviors $\quad$ infertility $\quad$ humans

Reproduction and Fertility (2021) 1 R13-R26

https://raf.bioscientifica.com

https://doi.org/10.1530/RAF-20-0046
(C) 2021 The authors Published by Bioscientifica Ltd

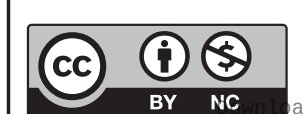

This work is licensed under a Creative Commons Attribution-NonCommercial 4.0 International License. 


\section{Introduction}

Reproduction is an important biologic event in all living organisms. Anything that threatens reproductive health will trigger a significant response from the scientific community, since the continuous existence of any species is dependent upon the sound reproductive health of the parent species. There are reports of deteriorating reproductive health indices since the last 5-6 decades ago from different parts of the world especially in industrialized/developed countries as a result of modifiable lifestyle factors (Kumar et al. 2018).

Lifestyle factors refer to the modifiable behavior and ways of life that could influence the general health and wellbeing of individuals including fertility (Acharya \& Gowda 2017). The role of lifestyle factors in the etiology of infertility has generated a growing interest among researchers. Several authors have provided evidence of an association between lifestyle behaviors and infertility in both men and women, they include; delayed childbearing due to pursuit of career or education, age of starting a family, smoking, eating of fat-rich diets, alcohol and caffeine consumption, exercise, risky sexual behaviors, drug misuse, anxiety/ depression, cellular phones and radiation among others (Araoye 2003, Adewumi 2017, Fehintola et al. 2017, Durairajanayagam 2018, Emokpae \& Chima 2018,
Ilacqua et al. 2018, Ikyernum et al. 2019, Silvestris et al. 2019, Alabi 2020) (Fig. 1).

According to the World Health Organization, about $20-30 \%$ of couples worldwide are infertile, and up to 80 million women are affected by the condition with about $50 \%$ of all women in developing countries are infertile (Ombelet et al. 2008). The prevalence of infertility in sub-Saharan African ranges between 20 and $40 \%$ and the problem is shared equally by both men and women (Emokpae \& Uadia 2015). It has been estimated that about one in six couples or approximately $15 \%$ of the population in industrially developed countries is affected (Sharma et al. 2013). Infertile couples suffer both emotional and psychological trauma due to pressure from family members and society. Fortunately, most of the causes of infertility are treatable with major procedures belonging to the assisted reproductive technology (ART) methods. However, the normalization of some modifiable lifestyle factors could restore normal oocyte maturation in women and improve semen quality in the males (Ilacqua et al. 2018). The understanding of the various mechanisms whereby modifiable lifestyle behaviors impair infertility in both males and females will go a long way to assist in the management of affected subjects. This review seeks to highlight the adverse effects of some lifestyle behaviors and suggests ways to optimize the infertile couple's chances of obtaining conception and live a better quality of life.

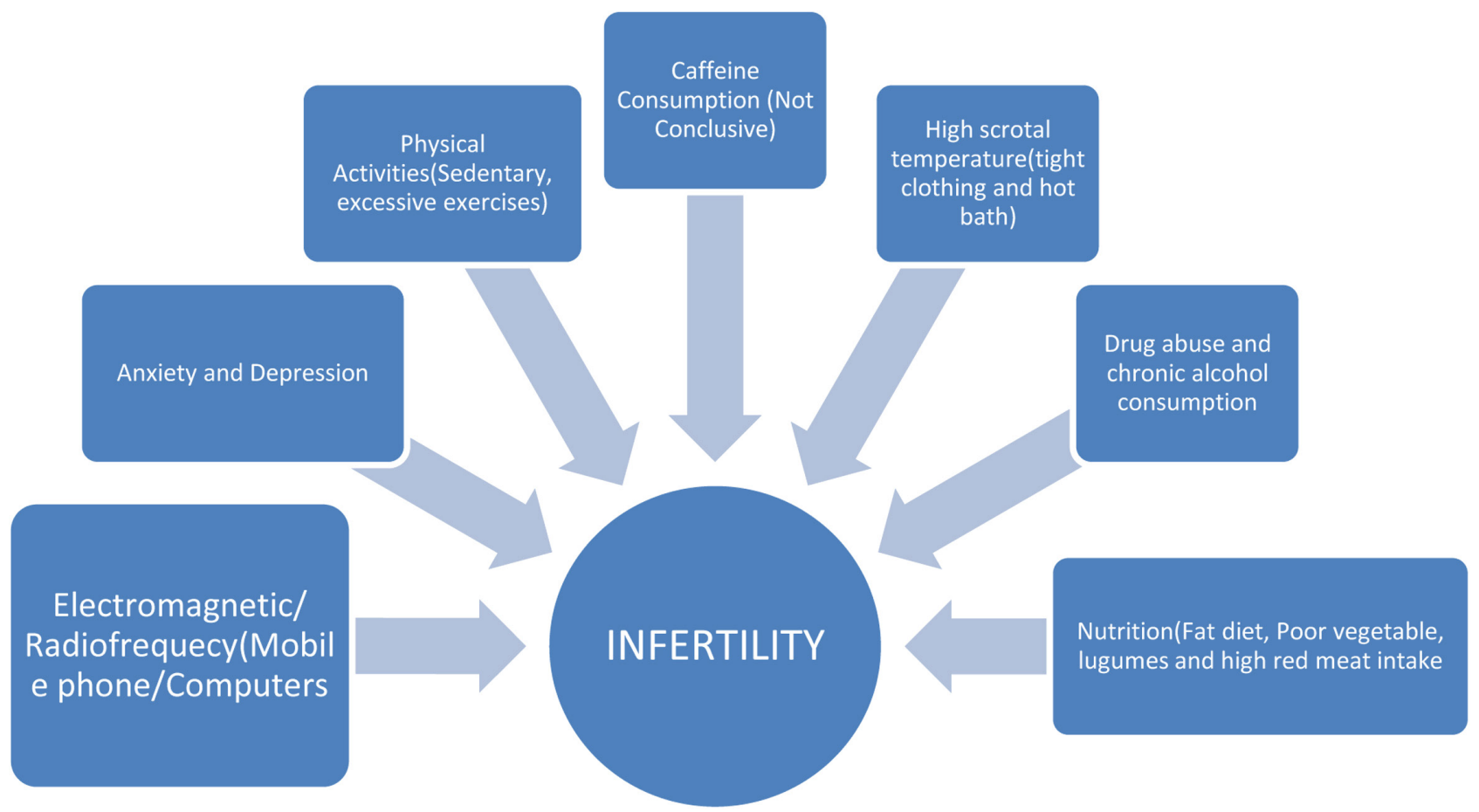

Figure 1 Schematic representation of lifestyle behaviors on infertility in both males and females.

https://raf.bioscientifica.com

https://doi.org/10.1530/RAF-20-0046 (c) 2021 The authors Published by Bioscientifica Ltd

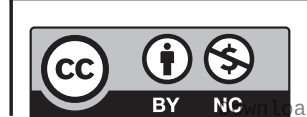

This work is licensed under a Creative Commons Attribution-NonCommercial 4.0 International License. ded from Bioscientifica.com at 04/26/2023 10:49:26AM 


\section{Materials and methods}

Over 1000 articles were initially identified from the Medline, Pubmed and Google scholar search engines and after review of the titles and abstracts, about 150 articles that met the inclusion criteria of major lifestyle factors associated with both male and female infertility were systematically reviewed. This narrative review is largely focused on Nigeria and the recommendations could be country-specific. The need to change the erroneous belief and perception of some Nigerians that children conceived through the assisted reproductive technique are 'artificial' is emphasized.

\section{Major lifestyle behaviors that may affect fertility}

Lifestyles factors are obviously under the control of the individual and are modifiable to improve the wellbeing of humans. Lifestyle factors could affect reproductive health either positively or negatively (Ilacqua et al. 2018). Infertility can be defined as the absence of conception within one year of unprotected sexual intercourse, while fertility is the capability of producing an offspring (Aydin et al. 2014). The new trend of modern lifestyle is that people delay starting a family due to educational and career pursuit, such individuals are older and overweight. Aging is associated with degenerative changes at the levels of all organs and systems, and as such fertility may be affected (Balasch \& Gratacós 2011). Consequently, such individuals engage in excessive alcohol consumption, tobacco intoxicated, and abuse illicit substances (Harris et al. 2011). These lifestyle behaviors expose one to the risk of infertility, but because of the financial stability that comes with having a career; most believed they can afford assisted reproduction. The causes of infertility are varied ranging from endometriosis, ovulatory disorders, poor sperm quality, and unexplained conditions among others. Some authors suggested that adverse lifestyle factors such as smoking, alcohol consumption, and caffeine can have an additive effect on fertility (Ilacqua et al. 2018). A study that examined couples who were trying to conceive naturally over 12 months, reported that only $38 \%$ of couples with 4 adverse lifestyle factors conceived compared to $52 \%$ with $3,62 \%$ with 2 , and $71 \%$ with one. Where no adverse lifestyle factors were present, $83 \%$ of couples became pregnant (Burton 2014).

\section{Delayed childbearing/age of starting a family}

Human reproduction is greatly influenced by age. This is because so many physiological changes take place both in men and women as they grow older (Emokpae \& Uadia 2017, Emokpae \& Igharo 2020). This is compounded by the powerful effect of socioeconomic and environmental factors which have not helped to improve reproductive potential despite improved technology and advancement in science.

Delay in starting a family/aging among men may lead to the production of poor quality spermatozoa. Semen parameters begin a steady decline as early as age 35 (Stone et al. 2013). Semen volume and motility decrease and morphology may become increasingly abnormal. Although age affects both males and females, the most significant impact on reproduction is maternal age. A woman is born with all egg cells she will ever have. They reduce in number and quality over the years and by the time she gets to 35 years, her fertility is declined (Baird et al. 2005). Incidence of genetic abnormality and spontaneous abortion also increases with maternal age (Kroon et al. 2011). A benchmark of natural fertility is usually provided by the Hutterite population which lives a relatively simple communal lifestyle that excludes the use of contraception. They showed a progressive decline in the rate of pregnancies with an increase in female age (Tyden et al. 2006). The data of Wood demonstrates that delay in starting a family and aging could lead to a 50\% decrease in apparent fertility potential at age 35 years. Fecundability is the ability to achieve a pregnancy within a menstrual cycle. This effect is also similar in women undergoing ART with decreased pregnancy rates with age (Liu et al. 2017). The biological clock regulating the female reproductive life span has existed to reduce the complications associated with abnormal pregnancy outcomes in advancing age and to save energy for somatic maintenance (Luo \& Murphy 2011, Emokpae \& Igharo 2020). Despite this substantial evidence of a decline in fertility with age, men and women are often unaware of the risk associated with delayed childbearing due to the increasing social behavior where education and career pursuits coupled with economic factors keep both gender out of relationships and childbearing until the late thirties and early forties (Luo \& Murphy 2011). Couples need to understand the biology of aging concerning fertility in both sexes to enable them and healthcare givers to make an informed decision regarding delayed childbearing, age of starting a family, and counseling of those seeking fertility treatments (Emokpae \& Igharo 2020). Although men could produce semen even at an older age, increased paternal age has been reported to be a major determinant for testicular function, sex hormones, sperm quality, sperm DNA integrity, telomere length, and

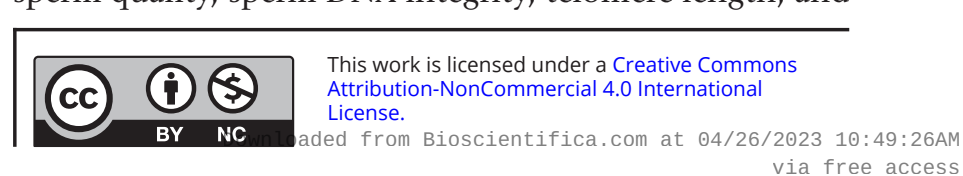


epigenetic factors (Arslan et al. 2017, Ilacqua et al. 2018). These changes due to aging adversely impact fertility and reproductive outcomes such as congenital birth defects, fetal death, recurrent abortion, and infertility. Paternal age has also been linked with autism, schizophrenia and bipolar disorders, and achondroplasia (Arslan et al. 2017). Higher oxidative stress occurs in aged couples as a result of an imbalance between reactive oxygen species generation and available antioxidants in the circulation. This was aptly demonstrated in an experimental study that showed that aging leads to a decline in fertility and the numbers of Sertoli and germ cells in mice with the complete absence of catalase (CAT-null(cat-/-) or/and superoxide dismutase 1 (SOD-null(sod-/-) (Tyden et al. 2006). This is an indication that these antioxidant enzymes are vital in the maintenance of germ cell quality in advanced age. Paternal age is reported to adversely affect testicular volume, alters the structure of seminiferous tubules (Janevic et al. 2014), and reduces blood supply to the testes (Wasiu et al. 2012). Sex hormone secretion is affected by aging; there is a decline in the secretion of testicular inhibin B by Sertoli cells coupled with increased secretion of follicle-stimulating hormone (FSH) (Ilacqua et al. 2018). Since there are reductions in the numbers of Leydig cells, the biosynthesis of testosterone is affected. Aging was also reported to alter the hypothalamic-pituitarygonadal axis function, hence leading to changes in the other reproductive hormones. The exacerbated effect of aging on increase DNA fragmentation was reported to be a contributing factor to the low success rate of assisted reproduction technology (ART) treatment in infertile couples (Alvarez Sedó et al. 2017). Individuals should be counseled to start a family at the peak of reproduction period as delay can adversely affect fertility potentials. Also, caution may be applied when using spermatozoa of aged-men during treatment with ART to avoid the risk of possible transmission of genetic disorders to offsprings.

\section{Nutritional factors}

Nutritional problems are strikingly different in developing nations where deprivation, undernutrition, and malnutrition are the major problems while eating disorders and obesity are very common in developed countries. Obesity is, however, increasingly common in developing countries due to globalization. The reproductive system is extremely sensitive to influences from the external environment. This is because it involves energy expenditures and it is only sensible that the physiological control mechanisms of the reproductive axis be closely linked to the nutritional status as it is in living organisms (Giahi et al. 2016). Several factors such as genetic, environmental and behavior contribute to the increasing trend in overweight and obesity. In some cases, the preponderant of cheap high-calorie but nutrient-poor foods in the last four decades has contributed to the high prevalence of obesity all over the world (Giahi et al. 2016).

In females, reproduction involves much greater energy expenditures than for males and as a protective mechanism against under-nutrition, ovarian activity is suppressed in women with eating disorders and exercise-induced amenorrhea through pathways in the hindbrain. The combined prevalence of Bulimia nervosa and Anorexia nervosa is approximately 5\% among women of reproductive age. Bulimia nervosa is an eating disorder that is characterized by binge eating which is followed by fasting or self-induced vomiting or purging. It is an emotional disorder that makes one have a distorted body image and an obsessive desire to lose weight. Anorexia on the other hand is also an eating disorder that is more of a psychological condition marked by extreme self-starvation due to a distorted body image. The likelihood of cure is higher with Bulimia nervosa. Both disorders suppress ovulation in severely affected women and account for up to $60 \%$ of women with anovulatory infertility (Tabler et al. 2018).

Some nutritional factors may affect male fertility and evidence suggesting a direct association between nutritional altitude and poor semen quality has emerged. High-fat diets inhibit reproduction by affecting the physical and molecular structure of not only sperm cells but also the developing fetus and offsprings (Rato et al. 2014). Some experimental studies have shown that feeding mice with high-fat diets resulted in long-term alterations in the reproductive system, and the metabolic programming mechanisms; such as a decrease in both height and diameter of the seminiferous epithelium, and seminiferous tubules, respectively (Ibáñez et al. 2017). This also resulted in decreased sperm concentration, viability, and DNA integrity. It has long been recognized that normal testicular function is responsive to changes in whole-body metabolism, and that testicular metabolism can be affected by the intake of high-energy diet (Rato et al. 2013) and in people with obesity. Studies have suggested that reproductive health can be enhanced by modification of dietary intakes such as fruits and vegetables, legumes, and fish. The regular intake of foods rich in fruits, vegetables, legumes, and fish was associated with better sperm quality (Karayiannis et al. 2017) and a lower DNA fragmentation index than subjects who do not

This work is licensed under a Creative Commons Attribution-NonCommercial 4.0 International License. 
take such foods regularly. Regular intake of red meat was inversely associated with sperm quality. Table 1 shows the schematic representation of various lifestyle behaviors on infertility.

In a study of health and lifestyle among Finnish men and women with infertility, it was reported that infertile women under 50 years consumed more unsaturated fat, less saturated fat, and consumed more alcohol than their fertile counterparts (Revonta et al. 2010). The effectiveness of lifestyle intervention was assessed among some infertile women with obesity, and the authors reported that lifestyle intervention increased the natural conception rate among anovulatory infertile women with obesity, but did not affect the rate of healthy live birth (van Oers et al. 2016). Infertile women are therefore counseled to maintain a healthy eating habit to avoid the accumulation of body fats with may impair ovulation (van Oers et al. 2016). The evaluation of lifestyle habits and the modification of unhealthy habits by trained health providers with specific management, like systematic folic acid supplementation in females attempting to conceive may yield the desired outcomes (Silvestris et al. 2019). High insulin levels and insulin resistance are associated with body fat accumulation, polycystic ovarian syndrome, metabolic syndrome, and all have serious implications for female infertility. Hyperinsulinemia enhances the excess biosynthesis of androgen and lipids from the theca cells. Increase production of estrogen by the fat cells and primary sex organs that occur in a state of high body fat is interpreted as birth control by the body, hence limiting the chances of conception (Wasiu et al. 2012).

\section{Smoking}

Cigarette smoking has been associated with adverse effects on fertility although not widely recognized. It also increases the risk of congenital cardiac disease. In males, smoking has been observed to reduce sperm concentration, morphology, and motility as well as increased DNA damage (Caserta et al. 2013). The exact mechanisms underlying the impact of smoking on sperm quality is not completely understood. Tobacco smoke contains several substances such as nicotine, cadmium, lead, superoxide, and hydroxyl radicals that can adversely affect reproductive health. Superoxide and hydroxyl radicals can take part in the Fenton reactions to produce hydrogen peroxide and ultimately caused oxidative stress and cause DNA damage (Taha et al. 2012). Cadmium and lead have been reported to cause DNA strand breaks while nicotine, superoxide, and hydroxyl radicals can induce dsDNA breaks in sperm DNA (Ilacqua et al. 2018). A study that evaluated the levels of DNA fragmentation index (DFI)

Table 1 Summary of study findings of lifestyle behaviors on infertility in Nigeria.

\begin{tabular}{|c|c|c|}
\hline Reference & Study design & Population size \\
\hline Alabi (2020) & Qualitative & 15 \\
\hline Emokpae et al. (2020) & Cross-sectional & 400 \\
\hline Akande et al. (2019) & Cross-sectional & 202 \\
\hline
\end{tabular}

Ikyernum et al. (2019)

Emokpae et al. (2019)

Osabuohien \&

Emokpae \& Chima

Adewumi (2017)

Okafor et al. (2017)

Emokpae \& Egho

(2017)

Osian et al. (2019)

Oremosu \& Akang

(2015)

Omoaregba et al.

Makanjuola et al.
Emokpae (2018)

(2018)

(2011)

(2010)

\begin{tabular}{|c|c|}
\hline Cross-sectional & 600 \\
\hline Experimental & 24 adult rabbits \\
\hline Experimental & 30 adult rabbits \\
\hline Cross-sectional & 122 \\
\hline Review & Several articles \\
\hline $\begin{array}{l}\text { Cross-sectional } \\
\text { survey }\end{array}$ & 589 \\
\hline $\begin{array}{l}\text { Experimental } \\
\text { study }\end{array}$ & 30 adult rabbits \\
\hline Survey & 348 \\
\hline Experimental & $\begin{array}{l}36 \text { adult Sprague- } \\
\text { Dawley rats }\end{array}$ \\
\hline Cross-sectional & 100 \\
\hline Case-control & 320 \\
\hline
\end{tabular}

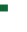

https://raf.bioscientifica.com

https://doi.org/10.1530/RAF-20-0046

\section{Type of lifestyle behaviors \\ Social, traditional and \\ religious beliefs \\ Nutrition \\ Perception and beliefs}

Risky sexually behavior

Drug abuse (tramadol)

Alcohol abuse

Paternal aging

Cultural beliefs/cost

Perception and

traditional belief

Alcohol abuse

Perception

Alcohol abuse

Anxiety and depression

Anxiety and depression
Reproductive health effect

Low acceptance of surrogacy practice

Poor semen quality

Poor acceptance surrogacy and negative attitude toward IVF treatment

Poor semen quality

Increased lipid peroxidation

Low sex hormone levels

High oxidative stress and apoptosis

High emotional/financial stress

Unscientific perception, misconception of IVF treatment Increased oxidative stress

Low knowledge of IVF

Low sex hormone levels, poor semen quality and high oxidative stress.

High psychological distress

High rate of psychiatric morbidity, lack of support from husbands' and husband's relatives. 
in infertile smokers and infertile non-smokers reported a significantly higher $(P<0.001)$ DFI $(37.66 \%)$ among infertile smokers than infertile non-smokers (19.34\%) and controls (14.51\%) (Wright et al. 2014). The study demonstrated the contribution of smoking to infertility. The effect of smoking on sperm quality was reported to be more pronounced in heavy smokers (those who smoke $>20$ cigarette sticks/day) and moderate smokers (10-20 cigarette sticks/day) than mild smokers (1-10 cigarette sticks/day) (Sharma et al. 2016).

In females, smoking can lead to the increased thickness of the zona pellucida in smokers which makes sperm penetration difficult (Ilacqua et al. 2018). Menopause has been reported to occur 1-4 years earlier in smoking women when compared to non-smoking women (Vanegas et al. 2017). Cigarette contains several harmful constituents that have been detected in the follicular microenvironment of smokers such as cotinine and cadmium thereby altering hormone levels in the luteal phase and could affect the developing follicle. Smoking in women significantly decreases the chance of conception by disrupting ovarian function and depleting its reserve.

Oxidative stress is one of the main causes of DNA fragmentation in male infertility but maybe modifiable in several ways. Sources of oxidative stress as outlined in this paper should be evaluated in infertile men as part of a treatment protocol. The use of antioxidants supplementation has been reported to have some benefits, but these antioxidant levels have to be determined whether there are deficiencies or not so that over-supplementation is avoided. It is important to maintain a delicate balance between oxidants/antioxidants to ensure fertility, successful fertilization, and pregnancy. Quitting smoking may improve fertility in those who smoke previously. A follow-up study of men who quitted smoking revealed that every additional year following cessation of smoking reduced the risk of ART failure by $4 \%$, especially between clinical pregnancy and live birth (Vanegas et al. 2017). Therefore, cessation of smoking and avoiding exposure to tobacco smoke among couples may improve the chances of conception.

\section{Alcohol consumption}

Alcohol is the most commonly abused substance known and used for celebration and relaxation since ancient times. Apart from damaging other organs of the body such as the liver, heart, and nervous system, it also affects reproductive health. The kind of damage done depends on the type, amount, and duration of alcohol consumption. Alcohol depletes many essential nutrients from the body such as vitamin B, zinc, iron, magnesium, calcium, sodium, potassium, etc., and these vitamins and minerals are needed for most functions including reproduction. There is excess estrogen and decrease testosterone in all types of alcohol misuse (Ilacqua et al. 2018). Alcohol is a known teratogen and its consumption has been reported to decrease fertility (Oremosu \& Akang 2015). An animal study that evaluated the effect of chronic alcohol consumption on reproductive hormones and semen characteristics, it was reported that serum testosterone, follicle-stimulating hormones (FSH), luteinizing hormone (LH), sperm count, and motility correlated inversely with increasing concentrations of alcohol consumed. Also, the concentration-dependent testicular morphological changes were observed (Osabuohien \& Emokpae 2018). It was observed that chronic consumption of alcohol did not only lower the levels of sex hormones and sperm quality but also led to weight loss in the animals as a result of changes in dietary habits (Osabuohien \& Emokpae 2018). Chronic alcohol consumption also alters macronutrients and micronutrients absorption in the small intestine. Studies have shown that the absorption of amino acids, lipids, and glucose is impaired during chronic over-consumption of alcohol. An earlier report indicated that chronic consumption of alcohol above $12 \% \mathrm{v} / \mathrm{v}$ concentration has the potential to increase serum markers of iron status and oxidative stress in experimental animals (Emokpae \& Egho 2017). The authors suggested that chronic ingestion of high concentrations of alcohol may have adverse effects on sex hormones, testes, epididymis, and ultimately fertility potential (Oremosu \& Akang 2015, Osabuohien \& Emokpae 2018). Therefore careful use of high concentrations of alcohol or better still abstinence is advised since alcohol suppresses the synthesis of hormones at the levels of the hypothalamus, the anterior pituitary, and the gonads (Oremosu \& Akang 2015, Osabuohien \& Emokpae 2018). Damage to the nervous system in men can results in sexual impotence due to loss of libido and erection (Durairajanayagam 2018).

Alcohol is commonly consumed by women of reproductive age and is associated with several reproductive health risks. There is no data on the prevalence of alcohol use and misuse in Nigeria but $86.4 \%$ of people aged 18 years and above are reported to have consumed alcohol at a point in their lives while $56 \%$ are current users in the United State of America (Abuse 2015). Studies in both human and animal models have observed that chronic

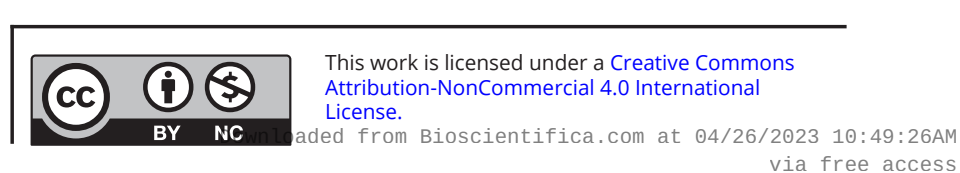


alcohol consumption resulted in changes in ovulation and menstrual cycle regularity (Oremosu \& Akang 2015). Although acute alcohol consumption may not harm the menstrual cycle, it has been reported to negatively affect fertility treatment outcomes. Chronic over-consumption of alcohol may lead to a decline in ovarian reserve and fertility potentials in women. Markers of ovarian reserve and fertility potentials (FSH, anti-mullerian hormone $(\mathrm{AMH})$ and antral follicle count) were reported to be lower among alcohol users than non-users (Abuse 2015). This was supported by evidence indicating that women who drink alcohol experience menopause at an earlier age than non-drinkers. On the contrary, there is no evidence linking mild or moderate alcohol consumption with female infertility. Some authors have reported no association between alcohol consumption and ovulation and fecundability (Mikkelsen et al. 2016). Even though the findings are inconsistent, individuals who are currently being treated for infertility maybe enjoined to abstain or reduce alcohol consumption.

A woman may suffer from infertility due to the derangement of the hormonal system by alcohol even with mild consumption. If she is pregnant there may be a risk of abortion and could also cause a low birth weight of the child with various congenital abnormalities if the pregnancy progresses.

Those who misuse alcohol early in life are more likely to indulge in risky sexual behavior which can expose them to sexually transmitted diseases such as Chlamydia trachomatis and HIV/AIDS. Sexually transmitted infections have been associated with infertility in several studies (Okonofua et al. 2005, Umeora et al. 2007). Genital tract infection is an important etiological factor for subfertility and infertility in Nigeria. It can lead to poor semen quality (Owolabi et al. 2013), obstruction of seminal tract (Okonofua et al. 2005) and tubal blockage (Umeora et al. 2007, Wasiu et al. 2012). Chronic dehydration is usually associated with heavy drinkers but appropriate hydration is important for a healthy reproductive function. Without enough water, men may experience poor quality erections, low seminal volume, and prostate infections. Women can develop persistent vaginal dryness and suffer greater susceptibility to a yeast infection.

\section{Alcohol consumption and the effectiveness of IVF treatment}

There is evidence that suggests that alcohol consumption negatively impacts ART treatment outcomes. A prospective study of 221 subjects undergoing IVF or gamete intra-fallopian transfer (GIFT) reported a 13\% decrease in the numbers of oocytes retrieved, a 2.86 times likelihood of not achieving pregnancy, and 2.21 times of higher risk of abortion among women who consume alcohol than controls (Klonoff-Cohen et al. 2003). These findings suggest fertilization failure, as alcohol intake can reduce the success rate of IVF treatment by decreasing oocyte yield and live birth rates. Therefore, women seeking IVF treatment are encouraged to abstain or minimize alcohol consumption before commencing treatment.

\section{Caffeine}

Caffeine is a stimulant that has enabled it to be used as a beverage (tea, soft drink, chocolate, etc.). It affects the nervous system and various other organs including the reproductive system. It has over 1000 active compounds (stimulants), and a high intake of caffeine more than 5 cups or $500 \mathrm{mg}$ per day delays pregnancy. It interrupts egg fertilization and implantation process (Olsen 2018). Several observational studies and meta-analyses have reported that maternal caffeine consumption may be associated with major adverse pregnancy outcomes. Some authors reported significant dose-dependent associations that are suggestive of causation while others observed no threshold of consumption below which associations were absent. Consequently, available data does not support health advice that assumes 'moderate' caffeine consumption during pregnancy is safe. However, current evidence supports pregnant women and would-be mothers to avoid caffeine consumption (James 2020). Conversely, the American College of Obstetrics and Gynecologist (2010) implied that moderate caffeine did not harm the fetus of pregnant women but its high intake (more than $540 \mathrm{mg}$ every day) resulted in low fetal weight and length. It also causes withdrawal symptoms such as headaches, nausea, irritability, etc. It may also increase the risk of miscarriage because it can cross the placenta barrier. A high level of caffeine consumption has been associated with an increased risk of stillbirth (Minguez-Alarcon et al. 2018). There is no definite amount or safe level of caffeine consumption but about $200 \mathrm{mg}$ is considered moderate for those breastfeeding, pregnant, or trying to conceive women.

The regular consumption and abuse of high caffeine energy drinks are increasingly popular. These caffeine-rich energy drinks have been reported to readily pass through biological membranes and rapidly distributed all over the body and may impair male gonadal development and function (Minguez-Alarcon et al. 2018). The mechanism by

This work is licensed under a Creative Commons Attribution-NonCommercial 4.0 International License. 
which caffeine impairs infertility is not well understood, and there are conflicting reports on its harmful effects by some authors (Ilacqua et al. 2018).

\section{Physical exercise}

Regular exercise affects all individuals' general health and wellbeing and probably provides some protection from obesity, cardiovascular disease, type 2-diabetes, psychological stress, etc. Exercise increases insulin sensitivity and improves ovarian functioning and may improve the chances of achieving conception. There is evidence to suggest an association between physical exercise and infertility, as exercise may contribute to a reduction in energy balance, leading to amenorrhea and irregular ovulation (Silvestris et al. 2019). Physical exercise is beneficial to overweight or obese infertile women. The findings from an interventional study indicated that physical exercise combined with weight loss was associated with improved fertility among obese women. On the contrary, a cohort study of over 5000 women with a healthy BMI range $\left(<25 \mathrm{~kg} / \mathrm{m}^{2}\right)$ showed that rigorous exercise was inversely associated with fertility potentials, but was positively associated with fecundability among overweight and women living with obesity (Wise et al. 2012). Sedentary lifestyle behavior refers to time spent doing little or no movement while awake or sitting. It is one important modifiable risk factor for infertility since biological evidence supports the association of physical activity and infertility. Women who engage in rigorous physical exercise may be at risk of infertility due to anovulation and implantation defect.

Most researches about physical fitness and reproduction are primarily focused on athletes rather than those with moderate level fitness. After BMI adjustment, each hour of vigorous exercise per week was reported to be associated with a $5 \%$ reduction in risk to protect ovarian functioning. However, in obese infertile women, increased physical fitness, and psychological wellbeing resulted in significant improvement in ovulation and conception (Silvestris et al. 2019). Female athletes who engage in excessive exercise and have poor dietary habits are at risk of developing a low BMI which may result in a low estrogen level. This affects the menstrual cycle and ovulation.

The quality of sperm parameters of men performing the exercise for one hour, at least three times a week were $15.2 \%$ better than that those who perform exercise less frequently or excessively (9.7\%). The parameters investigated by the authors were the morphology, count, concentration, and motility (Aydin et al. 2014). There are however conflicting data on the effect of physical exercise on male fertility potential. Earlier studies have indicated that regular vigorous exercise can adversely affect semen quality and testicular function, a situation attributed to testicular heating, oxidative stress, DNA fragmentation, and gonadotropin inhibition (Silvestris et al. 2019). Conversely, some authors have observed that individuals who engage in regular exercises had better semen quality than sedentary control subjects (LalindeAcevedo et al. 2017). Others have reported that moderate regular training may reduce seminal plasma oxidative stress than rigorous regular exercise (Silvestris et al. 2019). Regular moderate exercise is recommended and may improve fertility potential among infertile subjects since rigorous physical activities might expose individuals to an increased risk of poor reproductive function.

\section{Sexual behavior}

Sexual promiscuity greatly increases the risk of sexually transmitted diseases, such as gonorrhea, chlamydia trachomatis, herpes, syphilis, and HIV. Many of the sexually active individuals are less likely to use contraceptives which may lead to sexually transmitted infections (STIs), and unintended pregnancies. The increased risk of unplanned pregnancy and criminal abortions further aggravates the risk of STIs and infertility. Sexually transmitted infections (STIs) are common problems often associated with infertility in Nigeria (Emokpae \& Uadia 2015). Studies have associated STIs with risk for male infertility in southern Nigeria (Okonofua et al. 2005), and men who reported having chronic penile discharge, painful micturition, genital ulcers, and testicular pain were more likely to be infertile. Another study reported 173/500 (34.6\%) of STIs prevalence among males investigated for infertility in Kano, Northern Nigeria (Emokpae et al. 2009). Early diagnosis and treatment of STIs is key to the prevention of sexually transmitted infections-induced infertility.

\section{Drug abuse}

Women are more vulnerable to long-term drug abuse compared to men due to the difference in physiology, weight, hormone levels, etc., that can affect the breakdown of these drugs in the body (Center for Behavioral Health Statistics and Quality 2017). Heroin and methadone are known to cause amenorrhea. Intravenous drug use exposes one to HIV and AIDS and also when someone is under

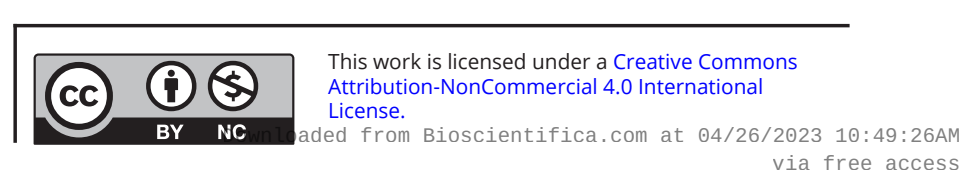


the influence of such drugs that individual can partake in risky sexual acts that make him or her susceptible to sexually transmitted infections (STI), including Human Papilloma Virus (HPV). This is linked to increased cervical cancer risk among women. Drugs such as marijuana, heroin, methamphetamine, cocaine could easily pass through the placenta to the fetus thereby increasing the risk of low birth weight, birth defects, premature birth, sudden infant death syndrome (SIDS), and changes in physical features of the fetus. Women who use illicit drugs during pregnancy are up to two times more likely to have a stillbirth, as prescription drugs such as non-steroidal anti-inflammatory drugs NSAID show a correlation with female infertility (Forray 2016).

In males, this risky behavior produces similar outcomes of STIs and infertility which usually presents with problems of sexual dysfunction. The use of methamphetamine and cocaine can lead to erectile dysfunction and delayed orgasm in men who initially may have experienced benefits such as heightened arousal. Chronic use of marijuana decreases testosterone secretion from Leydig cells, spermatogenesis, sperm motility, etc. (Forray 2016). Marijuana contains 'hashish' which also is capable of binding to receptors in a reproductive organ such as the uterus and ductus deference (Aydin et al. 2014).

\section{Cellular phones and radiation}

Emerging evidence suggests the detrimental effect of cellular phones on fertility. The numbers of mobile phone users are increasing by the day and several users keep and/or store mobile phones in their trouser pockets. The mobile phone has been suggested as a source of damaging radiation to the male reproductive organs. Increased levels of DNA fragmentation index have been reported in mobile phone users (Wright et al. 2014). These gadgets transmit or receive radiofrequency electromagnetic waves that have adverse effects on sperm motility, number, and morphology. Higher serum free testosterone and a lower luteinizing hormone (LH) level were reported among some users of cellular phones than control subjects who do not use cellular phones (Ilacqua et al. 2018).

\section{Anxiety and depression}

Some authors have observed that anxiety, depression, and violence could adversely impact fertility (Makanjuola et al. 2010). Studies in Nigeria have revealed how the varying forms of these habits affect fertility among infertile women. Procreation is considered as a means to enhance or solidify a woman's status in the family and community in Nigeria (Makanjuola et al. 2010). When this is not achieved as desired, marital harmony is threatened, anxiety and depression may occur. In a study of predictive factors for psychiatric morbidity among infertile women, it was observed that $48.8 \%$ out of 160 respondents presented with psychiatric morbidity. Also, the absence of support from their husbands and husband relatives, unfair treatment, discrimination, and induced abortion were significantly higher $(P<0.001)$ among infertile women than control subjects. The psychosocial challenges were not different between primary and secondary infertile women. The authors emphasized early identification of psychiatric morbidity and more public enlightenment to enhance moral and psychosocial support for women with infertility in Nigeria (Makanjuola et al. 2010). Surprisingly, the reported rate of psychiatric morbidity $(48.8 \%)$ was higher than previously reported from the same center. Some authors have reported a rate of $47.3 \%$ of psychiatric morbidity among infertile women from Akwa Ibom State in Nigeria. This is an indication that the challenge is widespread in Nigeria. Lack of support from their husbands, unfair treatment, and discrimination from their husbands and their relatives toward infertile women were associated with anxiety, depression and other psychosocial problems (Abasiubong et al. 2008, Bhonage et al. 2014).

There is enough scientific evidence to suggest that anxiety and depression could severely affect spermatogenesis, mainly by depressing testosterone secretion. The hypothalamic-pituitary-adrenal (HPA) axis has a direct inhibitory action on the hypothalamicpituitary-gonadal (HPG) axis and Leydig cells in the testes. The gonadotropin inhibitory hormone $(\mathrm{GnIH})$ also has an inhibitory effect on the HPG axis which results in a fall in the testosterone levels, which causes changes in Sertoli cells and the blood-testis barrier leading to the arrest of spermatogenesis (Makanjuola et al. 2010).

Anxiety and depression could activate an inhibitory effect on the female reproductive system. Corticotrophin releasing hormone (CRH) inhibits hypothalamic gonadotropin-releasing hormone (GnRH) secretion, and glucocorticoids inhibit pituitary luteinizing hormone and ovarian estrogen and progesterone secretion. These are responsible for the 'hypothalamic' amenorrhea (Abasiubong et al. 2008).

It is recommended that infertile couples desiring conception are encouraged to avoid anxiety and depression and management programs such as periodic relaxation

This work is licensed under a Creative Commons Attribution-NonCommercial 4.0 International License. 
activities are encouraged to improve conception rates (Silvestris et al. 2019).

\section{Perception and belief}

Another major challenge is the wrong perceptions and beliefs among the non-enlightened majority in developing countries particularly in West Africa about infertility and some of the available treatments (Adesiyun et al. 2011, Okwelogu et al. 2012, Okafor et al. 2017, Omokanye et al. 2017, Akande et al. 2019). Some believed that infertility is caused by evil spirits, predestined by God, punishment from God and supernatural challenge. Other perceived it as a curse that requires prayers and patience to be resolved (Okafor et al. 2017). This perception may not be limited to West Africa or Nigeria as a study from Karachi, Pakistan also revealed that evil forces and supernatural forces were considered as causes of infertility especially among people with low educational status (Akande et al. 2019). On the contrary, findings from several studies have shown infertility to be a disease condition or medical challenge rather than a social problem (Umeora et al. 2008, Okwelogu et al. 2012, Osian et al. 2019).

Advances in medical sciences have proven that infertile conditions are treatable. Various types of assisted reproductive technologies are available in the management of infertility. However, negative altitude, wrong perception and beliefs have been associated with IVF, which has been successfully used in the treatment of infertility especially among the un-enlightened individuals. Majority of respondents surveyed by some authors perceived IVF as un-natural and not cultural. The held perception of children conceived through this procedure is abnormal or inferior to those conceived naturally (Okafor et al. 2017, Akande et al. 2019). Despite the suggestion by earlier study that the wrong perception of IVF was due to the nascent nature of the technology (Giwa-Osagie 2002), the negative altitude and wrong perception still exists. As a result of misconception, lack of awareness and beliefs, ART treatment is conducted secretly to avoid stigmatization in Nigeria (Okafor et al. 2017). This may adversely impacts the treatment since seeking care for infertility is associated with supernatural forces, which requires supernatural methods to resolve. Lack of awareness of IVF in most countries of sub-Saharan Africa has posed a very strong challenge to its acceptability and utilization (Okafor et al. 2017).

The misconception and belief is very common among the uneducated and so strong that even the educated ones have some reservations due to the strong family support system being practiced. As a result, there is usually a delay in the willingness to access treatment because they want to 'wait on God' for the natural process of conception (Adesiyun et al. 2011, Omokanye et al. 2017). This practice further reduces the chances of hitherto healthy individuals that would have benefited from the treatment particularly those with unexplained infertility who could afford the cost of the technique. Therefore, individuals have a responsibility to preserve or increase their fertility potential to some degree by modifying their lifestyle behaviors which may improve or hamper their reproductive health. The authors advocate reproductive health education to create the necessary awareness of the etiologies of infertility and the importance of IVF treatment as a means of conceiving 'natural' babies.

\section{Some factors impairing effective treatment of infertility}

Some of the identified factors militating against the effective treatment of infertility include; high cost and inaccessibility of most couples in need, absence of specific objectives, priorities, and strategies for infertility care in most countries in sub-Saharan Africa, absence of reliable data and good follow-up mechanisms, lack of integration of infertility services into the reproductive health services, absence of proper coordination of healthcare system, inability to accurately target those at risk for infertility and inadequate training and research in infertility (Leke 2019). Some authors in Nigeria have observed that despite the great burden of the condition, only very few infertility management programs are available (Okafor et al. 2017). Fertility care, development, and access are limited. Therefore, the burden of infertility lies sorely on the couple (Akande et al. 2019). It was observed that most infertile couples belong to the very poor in the society, hence would not be able to afford the high cost of treatment (Agholor 2017), as a result, most couples discontinue or abandon their treatment. The most common cause of female infertility in Nigeria is a pelvic factor especially tubal blockage (probably due to post-infectious causes such as sexually transmitted infections, post abortal, and puerperal sepsis) and the best treatment is by Assisted Reproductive Technology methods. The cost of a cycle of in vitro fertilization is above one million Naira. To make matter worse, the success rate is low (20-30\%), and as such a couple may require more than one cycle to achieve success. This does not only lead to emotional and psychological trauma but increase poverty (Agholor 2017).

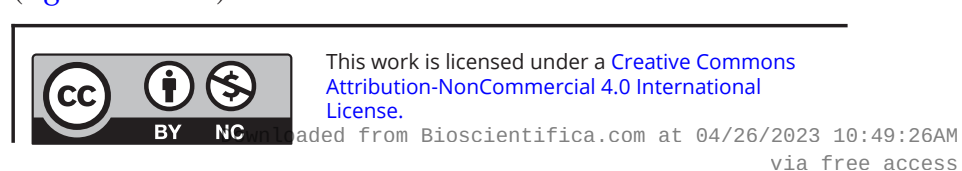


Stress is a modifiable factor that adversely impact treatment success of infertility. Stress is regarded as any uncomfortable 'emotional experience' accompanied by predictable biochemical, physiological, and behavioral changes or responses. Many forms of stress including physical, social, or psychological is a modern lifestyle, which can lead to reproductive treatment failure. Stress does not only lead to treatment failure but can cause infertility or it may arise from infertility (Aydin et al. 2014). The psychosocial-induced stress can affect fertility treatment if not avoided. It can lead to impaired gonadotrophin-release, low serotonin secretion, and elevated prolactin level. Also, it may cause abnormal function of the immune system which may adversely impact fertility-related antibodies (Aydin et al. 2014).

\section{Practical recommendations to modify lifestyle behaviors}

Age plays a major role in determining the fertility of both partners. Couples need to consider the age of the partners before marriage so that the chances of conception are increased. The peak of fecundability is before age 35 for men and 30 for women. Infertile couples should access care early after a maximum of one year without conception and 6 months among older couples.

Couples trying to achieve pregnancy should limit or quit smoking since there appears to be a significant impact of smoking on reproductive outcomes. The risk of miscarriage will be reduced and menopause will be delayed by 4 years. Also, passive smoking should be avoided.

Research shows that weight plays a significant role in fertility, therefore; maintaining a healthier weight will help to prevent hormonal imbalance which adversely affects fertility thereby improving ovulation and the risk of miscarriage and other complications. Overweight infertile women on treatment are encouraged to reduce weight for effective treatment outcomes.

It is better to reduce or abstain from alcohol consumption when trying to achieve pregnancy. Caffeine also appears to have a negative effect and should also be consumed with caution.

Infertile couples should avoid anxiety and emotional stress, but embark on relaxation programs to reduce other sources of stress to increase fertility. Moderate regular exercises could help to release endorphins which would help relaxation.

Nutrition and exercise may impact fertility both in men and women, good nourishment and a balanced diet should be encouraged. Infertile women should consume foods low in saturated fat, red meat, and high in vegetables, legumes, and antioxidants.

Recreational and prescription drugs have a significant impact on fertility as most of these drugs alter reproductive processes. It is therefore best to avoid all unnecessary medications and recreational drugs.

Avoiding excessive irradiation by reducing contact with electronic gadgets like mobile phones that emit electromagnetic waves may prevent infertility. It is not possible to eliminate all hazards in the environment, but efforts can be made to reduce them.

\section{Conclusion}

Most lifestyle factors are theoretically modifiable habits that can be reversed with strong determination by affected subjects. Public enlightenment by health care providers will go a long to increasing the knowledge and improve the awareness of the population since most are not aware of the potential consequences of lifestyle habits on infertility. Counseling of infertile couples may enhance awareness of the risk of lifestyle behaviors and facilitate appropriate lifestyle changes that might improve reproductive health. Educational and career pursuits could be combined with childbearing and the government should provide facilities such as day-care and nursery within the working environment to encourage prospecting mothers. Public health enlightenment campaigns that will educate on the harmful effects of drug and substance abuse should be intensified. Appropriate legislation and enforcement of laws that regulate these drugs coupled with the punishment of offenders may help to check the negative impact of substance abuse by individuals and society at large.

\section{Declaration of interest}

The authors declare that there is no conflict of interest that could be perceived as prejudicing the impartiality of this review.

\section{Funding}

This research did not receive any specific grant from any funding agency in the public, commercial or not-for-profit sector.

\section{Author contribution statement}

This work was conducted and approved in collaboration between the authors. M A designed the study; M A E, S I B contributed to literature search; S I B drafted the manuscript; M A E wrote the final manuscript; M A E proofread the manuscript. 


\section{References}

Abasiubong F, Bassey E, Ekett J, Umoiyoho A \& Umoh A 2008 The burden of psychological symptoms in gynaecological conditions among women in Uyo, Akwa Ibom, Nigeria. Nigerian Journal of Psychiatry 6 21-25.

Acharya S \& Gowda CR 2017 Lifestyle factors associated with infertility in a rural area: a cross-sectional study. International Journal of Medical Science and Public Health 6 502-506. (https://doi. org/10.5455/ijmsph.20170852309092016)

Adesiyun AG, Ameh N, Avidime S \& Muazu A 2011 Awareness and perception of assisted reproductive technology practice amongst women with infertility in Northern Nigeria. Open Journal of Obstetrics and Gynecology 1 144-148. (https://doi.org/10.4236/ojog.2011.13027)

Adewumi EA 2017 Infertility treatment financing in Nigeria. Nigerian Journal of Health Sciences 17 38-42. (https://doi.org/10.4103/njhs. njhs_28_16)

Agholor K 2017. The burden of infertility in Nigeria: Raising Visibility to Promote Equitable Access to Care. Maternal Health TaskForce, Harvard Chan School Center of Excellence in Maternal and Child Health. (https://www.mhtf.org/authors/kingsley-agholor/) Accessed 08/09/2020.

Akande SO, Dipeolu IO \& Ajuwon AJ 2019 Altitude and Willingness of infertile persons towards the uptake of Assisted Reproductive Technology in Ibadan, Nigeria. Annals of Ibadan Postgraduate Medicine 17 51-58.

Alabi OJ 2020 A qualitative investigation of surrogacy as a panacea for infertility in Nigeria. F1000Research 9 103. (https://doi.org/10.12688/ f1000research.20999.1)

Alvarez Sedó C, Bilinski M, Lorenzi D, Uriondo H, Noblía F, Longobucco V, Lagar EV \& Nodar F 2017 Effect of sperm DNA fragmentation on embryo development: clinical and biological aspects. JBRA Assisted Reproduction 21 343-350. (https://doi. org/10.5935/1518-0557.20170061)

American College of Obstetrics and Gynecologists 2010. ACOG Committee Opinion No. 462: Moderate Caffeine Consumption During Pregnancy. Obstetrics \& Gynecology 116 467-468. (https://doi. org/10.1097/AOG.0b013e3181eeb2a1)

Araoye MO 2003 Epidemiology of infertility: social problems of the infertile couples. West African Journal of Medicine 22 190-196. (https://doi.org/10.4314/wajm.v22i2.27946)

Arslan RC, Willführ KP, Frans EM, Verweij KJH, Bürkner P-C, Myrskylä M, Voland E, Almquist C, Zietsch B \& Penke L 2017. Older fathers' children have lower evolutionary fitness across four centuries and in four populations. Proceedings of the Royal Society B: Biological Sciences 284 379-385. (https://doi.org/10.1098/ rspb.2017.1562)

Aydin T, Karadag MA, Demir A, Cecen K, Karasu Y \& Ulker K 2014 Effect of modification of lifestyle on reproductive potential. Kafkas Journal of Medical Sciences 4 27-35. (https://doi.org/10.5505/ kjms.2014.64936)

Baird J, Fisher D, Lucas P, Kleijnen J, Roberts H \& Law C 2005 Being big and growing fast: systematic review of size and growth in infancy and later obesity. BMJ 331 929. (https://doi.org/10.1136/ bmj.38586.411273.E0)

Balasch J and Gratacós E 2011. Delayed Childbearing: Effects on Fertility and the Outcome of Pregnancy. Fetal Diagnosis and Therapy 29 263-273. (https://doi.org/10.1159/000323142)

Bhonage MB, Prasasd S, Jiloha RC, Ray PC, Mohapatra S \& Knower BC 2014 Effect of psychological stress on fertility hormone and seminal quality in male partners of infertile couples. Andrologia 47 336-342.

Burton P 2014. Lifestyle Factors and Fertility. Concept Fertility Center, Version 5:1-3. (https://www.conceptfertility.com.au/ files/3014/3331/1669/Lifestyle_Factors_and_Infertility_12-1-27_ UserTemp-5.pdf) Accessed 18/09/2019
Caserta D, Bordi G, Di Segni N, D'Ambrosio A, Mallozzi M \& Moscarini M 2013 The influence of cigarette smoking on a population of infertile men and women. Archives of Gynecology and Obstetrics 287 813-818. (https://doi.org/10.1007/s00404-012-2643-5)

Center for Behavioral Health Statistics and Quality 20172016 National Survey on Drug Use and Health: Detailed Tables. Substance Abuse and Mental Health Services Administration, Rockville, MD, USA . (https://www.samhsa.gov/data/sites/default/files/NSDUHDetTabs-2016/NSDUH-DetTabs-2016.pdf)

Durairajanayagam D 2018 Lifestyle causes of male infertility. Arab Iournal of Urology 16 10-20. (https://doi.org/10.1016/j.aju.2017.12.004)

Emokpae MA \& Chima HN 2018 Effect of senescence on some apoptosis and oxidative stress markers in infertile normozospermic and oligozoospermic men: a cross-sectional study. International Journal of Reproductive Biomedicine 16 435-442.

Emokpae MA \& Egho JA 2017 Chronic exposure to high alcohol concentrations in experimental animals may induce iron overload and oxidative stress. Biokemistri 29 24-30.

Emokpae MA \& Igharo OG 2020 Linking senescence, apoptosis and oxidative stress in fertility. In Aging: Oxidative Stress and Dietary Antioxidants, 2nd ed., pp. 113-123. Eds VR Preedy \& VB Patel. London, UK: Academic Press, Elsevier.

Emokpae MA, Ogunniyi OB, Dada GO \& Awopetu VI 2019. Alteration in the levels of some markers of Oxidative Stress and liver function induced by Tramadol Administration in Male Rabbits: the effect of its withdrawal. Journal of Medical Discovery 4 jmd18045. (https://doi.org/10.24262/jmd.4.1.18045)

Emokpae MA \& Uadia PO 2015 Male infertility in Nigeria: a neglected reproductive health issue requiring attention. Journal of Basic and Clinical Reproductive Sciences 4 45-53. (https://doi.org/10.4103/2278960X.161042)

Emokpae MA \& Uadia PO 2017 Potential risk of senescence on male fertility and sperm DNA damage on progeny. Tropical Journal of Natural Product Research 1 58-62. (https://doi.org/10.26538/tinpr/v1i2.3)

Emokpae MA, Uadia PO \& Nasir SM 2009 Contribution of bacterial infection to male infertility in Nigerians. Online Journal of Health and Allied Sciences 8 1-6.

Fehintola AO, Fehintola FO, Ogunlaja OA, Awotunde TO, Ogunlaja IP \& Onwudiegwu U 2017 Social meaning and consequences of infertility in Ogbomoso, Nigeria. Sudan Journal of Medical Sciences 129.

Forray A 2016 Substance use during pregnancy. F1000Research 5 F1000 Faculty Rev-887. (https://doi.org/10.12688/f1000research.7645.1)

Giahi L, Mohammadmoradi S, Javidan A \& Sadeghi MR 2016 Nutritional modifications in male infertility: a systematic review covering 2 decades. Nutrition Reviews 74 118-130. (https://doi. org/10.1093/nutrit/nuv059)

Giwa-Osagie OF 2002. Art in developing countries with a particular reference to sub-Saharan Africa. In Current Practices and Controversies in Assisted Reproduction. Eds E Vayena, PJ Rowe \& PD Griffin. Geneva, Switzerland: WHO.

Harris ID, Fronczak C, Roth L \& Meacham RB 2011 Fertility and the aging male. Reviews in Urology $\mathbf{1 3}$ e184-e190.

Ibáñez CA, Erthal RP, Ogo FM, Peres MNC, Vieira HR, Conejo C, Tófolo LP, Francisco FA, da Silva Silveira S, Malta A et al. 2017 A high fat diet during adolescence in male rats negatively programs reproductive and metabolic function which is partially ameliorated by exercise. Frontiers in Physiology 8 807. (https://doi. org/10.3389/fphys.2017.00807)

Ikyernum JA, Agbecha A \& Hwande ST 2019 Semen profile of men presenting with infertility at First Fertility Hospital, Makurdi, NorthCentral Nigeria. Clinical Medicine and Diagnostics 9 26-35.

Ilacqua A, Izzo G, Emerenziani GP, Balari C \& Aversa A 2018 Lifestyle and fertility: the influence of stress and quality of life on male fertility. Reproductive Biology and Endocrinology 16 115. (https:// doi.org/10.1186/s12958-018-0436-9)

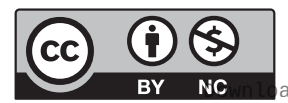

This work is licensed under a Creative Commons Attribution-NonCommercial 4.0 International License. ded from Bioscientifica.com at 04/26/2023 10:49:26AM 
James JE 2020 Maternal caffeine consumption and pregnancy outcomes: a narrative review with implications for advice to mothers and mothers-to-be. BMJ Evidence-Based Medicine 2020111432. (https://doi.org/10.1136/bmjebm-2020-111432)

Janevic T, Kahn LG, Landsbergis P, Cirillo PM, Cohn BA, Liu X \& Factor-Litvak P 2014 Effects of work and life stress on semen quality. Fertility and Sterility 102 530-538. (https://doi.org/10.1016/j. fertnstert.2014.04.021)

Karayiannis D, Kontogianni MD, Mendorou C, Douka L, Mastrominas M \& Yiannakouris N 2017 Association between adherence to the Mediterranean diet and semen quality parameters in male partners of couples attempting fertility. Human Reproduction 32 215-222. (https://doi.org/10.1093/humrep/dew288)

Klonoff-Cohen H, Lam-Kruglick P. \& Gonzalez C 2003 Effects of maternal and paternal alcohol consumption on the success rates of in vitro fertilization and gamete intrafallopian transfer. Fertility and Sterility 79 330-339. (https://doi.org/10.1016/s0015-0282(02)04582-x)

Kroon B, Harrison K, Martin N, Wong B. \& Yarsdani A 2011 Miscarriage karyotype and its relationship with maternal body mass index, age, and mode of conception. Fertility and Sterility 95 1827-1829. (https://doi.org/10.1016/j.fertnstert.2010.11.065)

Kumar S, Thaker R, Verma V, Gor M, Agarwal R \& Mishra V 2018 Occupational, environmental exposure and lifestyle factors: declining male reproductive health. Journal of Gynecology and Infertility 1 1-5.

Lalinde-Acevedo PC, Mayorga-Torres BJM, Agarwal A, du Plessis SS, Ahmad G, Cadavid ÁP \& Cardona Maya WD 2017 Physically active men show better semen parameters than their sedentary counterparts. International Journal of Fertility and Sterility $\mathbf{1 1}$ 156-165. (https://doi.org/10.22074/ijfs.2017.4881)

Leke RJI 2019. The prevalence of infertility and its preventive measures in sub-Saharan Africa. Presentation at the WHO, AFRO and EMRO Regional management of infertility workshop 2019. (https:// www.gfmer.ch/Medical_education_En/Cameroon/Pdf/Infertility_ prevalence.pdf) Accessed 08/09/2020.

Liu KE, Case A \& Cheung AP 2017 Advanced reproductive age and fertility. International Journal of Gynecology and Obstetrics 39 685-695.

Luo S \& Murphy CT 2011 Caenorhabditis elegans reproductive aging: regulation and underlying mechanisms. Genesis 49 53-65. (https:// doi.org/10.1002/dvg.20694)

Makanjuola AB, Elegbede AO \& Abiodun OA 2010 Predictive factors for pyschiatric morbidity and women with infertility attending a gynaecology clinic in Nigeria. African Journal of Psychiatry 13 36-42.

Mikkelsen EM, Riis AH, Wise LA, Hatch EE, Rothman KJ, Cueto HT \& Sorenson HT 2016 Alcohol consumption and fecundability: a prospective Danish cohort study. BMJ 31 i4262.

Minguez-Alarcon L, Chavarro JE \& Gaskins AJ 2018 Caffeine, alcohol, smoking and reproductive outcomes among couples undergoing assisted reproductive technology treatment. Fertility and Sterility 110 587-592. (https://doi.org/10.1016/j. fertnstert.2018.05.026)

Okafor NI, Joe-Ikechebelu NN \& Ikechebelu JI 2017 Perceptions of infertility and in-vitro fertilization treatment among married couples in Anambra State, Nigeria. African Journal of Reproductive Health $2 \mathbf{1}$ 55-66. (https://doi.org/10.29063/ajrh2017/v21i4.6)

Okonofua F, Menakaya U, Onemu So, Omo-Aghoja LO \& Bergstrom SA 2005 Case-control study of risk factors for male infertility in Nigeria. Asian Journal of Andrology 7 351-361. (https:// doi.org/10.1111/j.1745-7262.2005.00046.x)

Okwelogu IS, Azuike FC, Ikechebelu SI \& Nnebue CKC 2012 In vitro-fertilisation practice: awareness and perceptions among women attending fertility clinics in Okija, Anambra State, Nigeria. AFRIMEDIC Journal 3 6-10.

Olsen N 2018. The effects of caffeine on your body. Health line newsletter, (https://www.healthline.com/health/caffeine-effectson-body) Accessed 10/09/2019.
Ombelet W, Cooke I, Dyer S, Serour G \& Devroey P 2008 Infertility and the provision of infertility medical services in developing countries. Human Reproduction Update 14 605-621. (https://doi. org/10.1093/humupd/dmn042)

Omoaregba JO, James BO, Lawani AO, Morakinya o \& Olotu OS 2011. Psychosocial characteristics of female infertility in a tertiary health institution in Nigeria. Annals of African Medicine 10 19-24. (https://doi.org/10.4103/1596-3519.76567)

Omokanye LO, Olatinwo AO, Durowade KA, Raji ST, Biliaminu SA \& Salaudeen GA 2017 Assisted reproduction technology: perceptions among infertile couples in Ilorin, Nigeria. Saudi Journal for Health Sciences 6 14-18.

Oremosu AA \& Akang EN 2015 Impact of alcohol on male reproductive hormones, oxidative stress and semen parameters in Sprague-Dawley rats. Middle East Fertility Society Journal 20 114-118. (https://doi.org/10.1016/j.mefs.2014.07.001)

Osabuohien DO \& Emokpae MA 2018 The impact of chronic alcohol consumption on sex hormones and semen parameters in male rabbits. Nigerian Health Journal 18 148-156.

Osian EA, Afemikhe JA, Olorunfemi o \& Eweka A 2019 Knowledge and perception of assisted reproductive technology among women attending the University of Benin Teaching Hospital, Benin City, Nigeria. Journal of Nursing and Midwifery Sciences 6 $125-130$

Owolabi AT, Fasubaa OB \& Ogunniyi SO 2013 Semen quality of male partners of infertile couples in Ile-Ife, Nigeria. Nigerian Journal of Clinical Practice 16 37-40. (https://doi.org/10.4103/11193077.106729)

Rato L, Alves MG, Cavaco JE \& Oliveira PF 2014 High-energy diets: a threat for male fertility? Obesity Reviews 15 996-1007. (https://doi. org/10.1111/obr.12226)

Rato L, Alves MG, Dias TR, Lopes G, Cavaco JE, Socorro S \& Oliviera PF 2013. High-energy diets may induce a pre-diabetic state altering testicular glycolytic metabolic profile and male reproductive parameters. Andrology 1 495-504. (https://doi.org/10.1111/j.20472927.2013.00071.x)

Revonta M, Raitanen J, Sihvo S, Koponen P, Klemetti R, Männistö S \& Luoto R 2010 Health and life style among infertile men and women. Sexual and Reproductive Healthcare 1 91-98. (https:// doi.org/10.1016/j.srhc.2010.06.002)

Sharma R, Biedenharn KR, Fedor JM \& Agarwal A 2013 Lifestyle factors and reproductive health: taking control of your fertility. Reproductive Biology and Endocrinology 11 66. (https://doi. org/10.1186/1477-7827-11-66)

Sharma R, Harlev A, Agarwal A \& Esteves SC 2016. Cigarette smoking and semen quality: a new meta-analysis examining the effect of the 2010 World Health Organization laboratory methods for the examination of human semen. European Journal of Urology 70 635-645. (https://doi.org/10.1016/j. eururo.2016.04.010)

Silvestris E, Lovero D \& Palmirotta R 2019 Nutrition and female fertility: an independent correlation. Frontiers in Endocrinology 10 346. (https://doi.org/10.3389/fendo.2019.00346)

Stone BA, Alex A, Werlin LB \& Marrs RP 2013 Age threshold for charges in Semen parameters in men. Fertility and Sterility $\mathbf{1 0 0}$ 952-958. (https://doi.org/10.1016/j.fertnstert.2013.05.046)

Tabler J, Utz RL, Smith KR, Hanson HA\& Geist C 2018 Variations in reproductive outcomes of women with histories of bulimia nervosa, anorexia nervosa or eating disorder not otherwise specified relative to the general population and closest aged sister. International Journal of Eating Disorders 51 102-111. (https://doi.org/10.1002/ eat.22827)

Taha EA, Ez-Aldin AM, Sayed SK, Ghandour NM \& Mostafa T 2012 Effect of smoking on sperm vitality, DNA integrity, seminal oxidative stress, zinc in fertile men. Urology 80 822-825. (https://doi. org/10.1016/j.urology.2012.07.002)

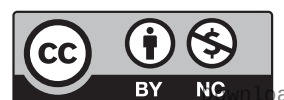

This work is licensed under a Creative Commons Attribution-NonCommercial 4.0 International License. ded from Bioscientifica.com at 04/26/2023 10:49:26AM 
Tyden T, Svanberg AS, Karlstrom PO, Lihoff L \& Lampic C 2006 Female university students' attitudes to future motherhood and their understanding about fertility. European Journal of Contraception and Reproductive Health Care 11 181-189. (https://doi. org/10.1080/13625180600557803)

Umeora OU, Mbazor JO \& Okpere EE 2007 Tubal factor infertility in Benin City, Nigeria - sociodemographics of patients and aetiopathogenic factors. Tropical Doctor 37 92-94. (https://doi. org/10.1177/004947550703700211)

Umeora OUJ, Igberase GO, Okogbenin SA \& Obu ID 2008. Cultural misconceptions and emotional burden of infertility in South East Nigeria. The Internet Journal of Gynaecology and Obstetrics 10 (https:// ispub.com/IJGO/10/2/3277)

van Oers AM, Groen H, Mutsaerts MA, Burggraaff JM, Kuchenbecker WK, Perquin DA, Koks CA, van Golde R, Kaaijk EM, Schierbeek JM et al. 2016 Effectiveness of lifestyle intervention in subgroups of obese infertile women: a subgroup analysis of a RCT. Human
Reproduction 31 2704-2713. (https://doi.org/10.1093/humrep/ dew252)

Vanegas JC, Chavarro JE, Williams PL, Ford JB, Toth TL, Hauser R \& Gaskins AJ 2017 Discrete survival model analysis of a couple's smoking pattern and outcomes of assisted reproduction. Fertility Research and Practice 3 5. (https://doi.org/10.1186/s40738017-0032-2)

Wasiu EO, Adebayo AA \& Taiwo AB 2012 A review of female infertility: important etiological factors and management. Journal of Microbiology and Biotechnology Research 2 379-385.

Wise LA, Rothman KJ, Mikkelsen EM, Sorensen HT, Riis AH \& Hatch EE 2012 A prospective cohort study of physical activity and time to pregnancy. Fertility and Sterility 97 1136.e1-1142.e1. (https:// doi.org/10.1016/j.fertnstert.2012.02.025)

Wright C, Milne S \& Leeson H 2014 Sperm DNA damage caused by oxidative stress: modifiable clinical, lifestyle and nutritional factors in male infertility. Reproductive Biomedicine Online 28 684-703. (https://doi.org/10.1016/j.rbmo.2014.02.004)

Received in final form 8 December 2020

Accepted 17 December 2020

Accepted Manuscript published online 17 December 2020 (c) 2021 The authors Published by Bioscientifica Ltd
This work is licensed under a Creative Commons Attribution-NonCommercial 4.0 International License. 